

\title{
Eficiência econômica, eficácia procedural ou efetividade social: Três valores em disputa na Avaliação de Políticas e Programas Sociais ${ }^{1}$
}

\author{
Economic efficiency, procedural \\ effectiveness or social effectiveness:Three \\ values in dispute in the Evaluation of Policies \\ and Social Programs
}

* Poulo de Mortino Jornnuzzi

\begin{abstract}
Resumo
O objetivo do texto é discutir a subjetividade e parcialidade implícitas nas Avaliações de Políticas e Programas, explicitando alguns dos valores e princípios que as regem. Depois de um breve debate sobre os mitos da objetividade absoluta e da pretensa superioridade epistêmica do método quantitativo no campo, o texto avança na discussão dos valores e critérios de mérito subjacentes às concepções políticos-ideológicas das avaliações: Eficiência econômica, eficácia procedural e efetividade social. Apresenta-se a concepção de Estado, de Políticas Públicas e o marco metodológico de Avaliação que cada valor público determina.
\end{abstract}

Palavras-chave: Avaliação de Programas, Políticas Públicas, Valores Públicos.

\begin{abstract}
The purpose of this paper is to discuss the subjectivity and bias implicit in the Evaluations of Policies and Programs, explaining some of the values and principles that govern them. After a brief discussion of the myths of absolute objectivity and the alleged epistemic superiority of the quantitative method in the field, the text advances in the discussion of values and merit criteria underlying the political-ideological conceptions of evaluations: Economic efficiency, procedural efficacy and social effectiveness. It presents the conception of State, of Public Policies and the methodological framework of Evaluation that each public value determines.
\end{abstract}

Keywords: Program Evaluation, Public Policies, Public Values

\footnotetext{
* É professor da Escola Nacional de Ciências Estatística do IBGE, no programa de pós-graduação População, Território e Estatísticas Públicas. Pesquisador PQ/CNPq no projeto "Políticas Públicas, Mudança Social e Dinâmica Demográfica no Brasil de 1992 a 2014.

E-mail: Paulo.jannuzzi@ibge.gov.br
} 


\section{Apresentação}

Objetividade e neutralidade são princípios recorrentemente citados como fundamentais na Avaliação de Políticas e Programas, especialmente em manuais de organizações multilaterais de fomento. Afinal, em uma cultura de Políticas Públicas focada em resultados, as recomendações das Avaliações só seriam aceitas por todos os interessados - políticos, gestores, academia, mídia e sociedade - se estivessem respaldadas na mais isenta e robusta pesquisa científica. Nessa perspectiva, somente estudos conduzidos segundo os preceitos da "insuspeita" Evidence-based Policy Making (Políticas Públicas baseada em evidências) ${ }^{2}$ se conseguiria prover alguma racionalidade técnica para os ineficazes programas sociais existentes nos países do Sul, trazendo a ordem econômica e o progresso material para as sociedades subdesenvolvidas.

Embora a tese da natureza contingencial e humana da produção científica e tecnológica já seja de largo conhecimento de pesquisadores com formação nas Ciências Sociais, a vivência na Administração Pública revela que o positivismo comteano está muito mais presente que se imagina, em especial, entre equipes técnicas envolvidas nos processos de formulação, avaliação e controle de Políticas e Programas Sociais (YANES, 2009). A assertiva "dados e fatos falam por si" ainda é partilhada com vigor em comunidades de Monitoramento e Avaliação (M\&A) alinhadas à "escola" da Políticas Públicas baseadas em evidências e/ou da recém-constituída Políticas Públicas determinada pelas normas e decisões judiciais e de órgãos de controle (Rules-dictated Policy Making) ${ }^{3}$. O campo de estudos em M\&A seria uma subdisciplina da Física Social, cabendo aos pesquisadores e agentes dessas escolas a busca de "leis universais" acerca do funcionamento das Políticas Públicas e "soluções iluminadas" de como garantir seu pleno funcionamento.

Adiantando uma das teses desse artigo, por mais que isso possa soar desconfortável para algumas comunidades epistêmicas e de práticas no campo de $M \& A$, não há produção tecnocientífica neutra e infalível, nem método e técnica com maior cientificidade que outras no desenvolvimento das atividades de monitoramento e avaliação de programas. Em uma ou outra perspectiva, evidências de pesquisas e de auditorias revelam "verdades" que derivam de escolhas ou apostas anteriores explícitas ou não - acerca de valores político-ideológicos e de princípios epistêmicos acerca da produção de conhecimento em Políticas Públicas. Como todo campo de conhecimento, a avaliação de políticas e programas é uma atividade humana, orientada por valores ideológicos e paradigmas diversos, regida por métodos e técnicas validadas por diferentes comunidades epistêmicas, produzindo resultados contingentes, que podem ser confirmados, refutados ou superados, em algum momento, por novas investigações. Ou então não seriam produção técnica-científica. Falibilidade do conhecimento técnico é antes uma virtude que uma fragilidade; denota antes a natureza científica e não dogmática do mesmo (SACCO, 2016). 
Desnudar a subjetividade e parcialidade implícitas nas Avaliações de Políticas e Programas, explicitando alguns dos valores e princípios que as regem é o objetivo desse texto, avançando a argumentação iniciada em oportunidades anteriores. Em Jannuzzi (2016a) apresentou-se as três ênfases institucionais que orientam a estruturação de rotinas, equipes e técnicas de Sistemas de M\&A: foco na identificação do custoefetividade das Políticas e Programas; foco na transparência da ação governamental e foco no aprimoramento do desenho e da gestão das Políticas e Programas. Em Jannuzzi (2016b) procurou-se evidenciar a conexão entre concepção de Estado e modelo requerido de Avalições de Políticas e Programas. Aqui se avança na discussão dos valores e critérios de mérito subjacentes às concepções políticos-ideológicas das avaliações. Eficiência econômica, eficácia procedural e efetividade social são os três valores estruturantes aqui discutidos, pela conexão direta com três perspectivas diferentes de elaboração de Avaliações em disputa no país, orientadas pela primazia da "qualidade do gasto público", da "conformidade processual" ou do "aprimoramento em busca de maior impacto social" das Políticas e Programas Públicos.

Ao se inspirarem em distintas concepções de Justiça e de como ela deve ser alcançada, cada um desses valores públicos, certamente legítimos e desejáveis em qualquer empreitada em Políticas Públicas, orienta as escolhas do que será avaliado, de como será avaliado e, em boa medida, do que será apontado como resultados principais do estudo avaliativo. Essa é uma primeira hipótese de trabalho desse trabalho; a segunda, mais do que uma hipótese, é a defesa da tese da primazia da Efetividade Social como valor fundante das Avaliações de Políticas e Programas no Brasil, na medida em que justiça, equidade e bem-estar social são princípios consagrados pela Constituição de 1988 e de várias convenções e compromissos internacionais assumidos pelo país ${ }^{4}$. Afinal, Política Pública guiada por princípios de equidade social (Equity-guided Policy Making) requer valores e ritos de avaliação muito além daqueles em se assentam as evidências produzidas nos laboratórios de econometria, em tribunais ou em escritórios distantes da operação das políticas e programas $^{5}$.

"Para qual finalidade republicana se faz Avaliações de Políticas e Programas" é uma pergunta poucas vezes feita e, menos ainda, respondida nas comunidades epistêmicas e de práticas de avaliação no país e no exterior. Muito pouco se discute sobre o contexto político e condicionantes ideológicos por detrás da aparente couraça "objetiva" que se revestem as Avaliações norteadas pelas tradições da Evidence-based ou da Rules-dictated Policy Making. Para além do debate de métodos e técnicas empregados nas pesquisas de avaliação, dos universos e amostras selecionadas, dos testes de hipóteses e dos níveis de significância é necessário discutir em que medida concepções de Estado e de Política Pública moldam a produção do conhecimento na área. É o que se procura fomentar por meio desse trabalho ensaístico. 


\section{A pretensa objetividade absoluta dos métodos e técnicas das Avaliações}

Como toda área de conhecimento técnico-científico em que há volume significativo de recursos para pesquisa e potencial prestígio político para as comunidades de pesquisadores praticantes, Monitoramento e Avaliação de Políticas e Programas Públicos constitui um campo de estudos aplicados com crescente produção e de intensa disputa técnica no país e no exterior. Lá fora e aqui dentro, os recursos de órgãos públicos e de agências multilaterais tem viabilizado a formação, manutenção ou expansão de equipes técnicas em universidades, centros de pesquisas e organizações não governamentais dedicadas ao tema, com produção de estudos avaliativos e instrumentos de monitoramento sobre variados temas, com repercussão menor ou maior no setor público, mídia e sociedade.

A julgar pela qualidade técnica e respeitabilidade institucional das equipes e centros de pesquisa envolvidos, muito do que se produz é, certamente, consistente do ponto de vista técnico e útil, direta ou indiretamente, para análise de Políticas Públicas e para a gestão de programas sociais. Ademais, a robustez metodológica e relevância substantiva dessa produção é atestada pelo fato de que boa parte dela é apresentada em seminários de pesquisadores, debatida em oficinas técnicas com gestores de políticas e programas e também veiculada em publicações técnico-científicas, com avaliação externa de especialistas.

Mas é preciso apontar que nem tudo o que se produz, se apresenta e se publica, contudo, mesmo por equipes e instituições experientes, resistiria a uma análise do mérito técnico de sua apropriação para aprimoramento do desenho, gestão ou avaliação de políticas e programas, propriedade certamente desejável em qualquer produto ou relatório no campo aplicado de $M \& A$. As disfunções e distorções desse acervo menos meritório da pesquisa aplicada na área se revelam por diferentes sintomas. Há trabalhos que, embora cumpram os requisitos técnicos necessários para sua legitimação científica (nas comunidades epistêmicas em que são produzidos), não parecem responder perguntas relevantes, pela ambiguidade ou generalidade dos achados, ou ainda pelos recortes a que a questão e o universo de análise vieram a sofrer para se encaixar na técnica. Na área, há certa mistificação na elaboração de parte destes estudos, que vai da fetichização da técnica à mitificação meta-científica ou metapolítica dos mesmos, em detrimento da transparência metodológica, lisura ética e responsabilidade republicana que avaliações de programas - mais ainda que trabalhos acadêmicos - devem dispor. Em alguns estudos, os indicadores tomam lugar dos conceitos que os originaram, como por exemplo, assumir como desenvolvimento humano o que a medida - Índice de Desenvolvimento Humano - revela, não o que o substantivamente se propõe como conceito (IEO 2016) ${ }^{6}$. O sociometrismo empiricista, isto é, a construção de indicadores pela combinação de outras medidas sem um claro marco conceitual ou normativo ganha autonomia como campo de pesquisa 
aplicada, oferecendo mensurações - com várias casas decimais - para qualquer que seja a dimensão analítica que se queira apreender. Em outros casos, a compulsão pela medida "mais precisa possível" do que se imagina ser o impacto de programas deixa em segundo ou terceiro planos os esforços de obtenção de indicadores de contexto e processo que podem ajudar a entender o sucesso e insucesso dos programas ${ }^{7}$.

Há estudos em que parece que a escolha do objeto de análise - da política ou programa - é ditada pela possibilidade de aplicação do método, e não pela relevância social da questão ou dos problemas elencados pelos gestores e técnicos, para serem respondidas. A impressão que se tem em boa parte desses trabalhos é que a suposta clareza e "beleza estética" da formulação matemática ou do desenho da pesquisa de campo orienta a escolha do objeto a ser investigado e não o contrário. A compulsão por encontrar relações de causalidade e atribuição acabam tornando-se mais importantes que investigar resultados junto a segmentos mais amplos da população beneficiária das políticas ou responder as perguntas que técnicos e gestores tem sobre as dificuldades de implementação dos programas. O método determina o que se quer responder, qualquer que seja a natureza da intervenção (MORAL-ARCE, 2014) ${ }^{8}$. Há ainda situações em que determinadas comunidades disciplinares se arvoram de detentoras dos únicos métodos legítimos de avaliação de programas, como a dos "randomistas" como bem os classificou o "insuspeito" Ravaillon (2009)9. Como explicitado pelos autores de um dos manuais clássicos nessa linha:

As avaliações de impacto fazem parte de uma agenda mais ampla: a da formulação de políticas com base em evidências. Essa crescente tendência global está marcada por uma mudança no enfoque, de insumos para resultados (......)

O monitoramento e a avaliação estão no cerne da formulação de políticas com base em evidências. Fornecem um núcleo básico de ferramentas que as partes interessadas podem usar para verificar e melhorar a qualidade, eficiência e efetividade das intervenções nas várias etapas de execução ou, em outras palavras, focar em resultados. (.....) Neste sentido, a informação e as evidências se tornam meios para facilitar a conscientização do público e promover a responsabilidade governamental. (....) Em um contexto no qual os formuladores de políticas e a sociedade civil exigem resultados e cobram prestação de contas dos programas públicos, a avaliação de impacto pode oferecer evidências críveis e robustas quanto ao desempenho e, fundamentalmente, quanto a se um programa específico atingiu os resultados desejados. (GERTLER et al, 2015, p.3-4).

A crença de que avaliações de impacto experimental ou suas variações constituem-se no padrão-ouro é reforçada, em um círculo "autorreferenciado" pelos bancos multilaterais de fomento e outras comunidades de financiadores de projetos sociais. Essas instituições, em geral, constituídas por equipes com formação acadêmica marcadamente disciplinar e positivista, com pouco conhecimento de desenho e prática de gestão de programas, reforçam a lógica perversa professada por essa comunidade epistêmica: só colocam recursos em iniciativas em que o gestor se compromete a seguir a cartilha prévia da avaliação de impacto, qualquer que seja a natureza da intervenção, 
viabilidade operacional do delineamento ou os princípios éticos a obedecer. É o que La Rovere (2014) discute, no contexto de avaliação de políticas ambientais, em que a investigação de contribuições marginais de iniciativa na área e a separação de unidades investigadas em amostra de tratamento e de controle é operacionalmente inviável. E desnuda como funciona o círculo de financiamento-método-financiamento de projetos e programas:

Yet pressure arising from multiple sources (donors and evaluation fora) towards the perceived higher rigour achievable through quantitative approaches and attribution is being reapplied on impact assessment and evaluation practitioners. This demand is stimulated (or often enforced) by major donors insisting that a quantitative approach is the only credible one.

These influential donors are almost always located in the same places (i.e. countries, cities and often intellectual circles) as the academic institutions where such tools are being promoted (LA ROVERE, 2014, p. 285).

Se não há como discordar quanto aos propósitos almejados pelos randomistas em contribuir para o aprimoramento do gasto público, há que refutá-los acerca da presunção da avaliação de impacto como "padrão-ouro" de Avaliação de Programas. Sob o mantra da Evidence-based Policy Making, a avaliação de programas reduz-se muitas vezes a exercícios aplicados de econometria, em que variações de um mesmo modelo-padrão são "rodados", sem efetiva verificação de pressupostos desejáveis na implementação dos programas ou quanto às propriedades necessárias dos dados empíricos. Supõem-se que os resultados de programas são univariados, quando se sabe que, no desenho dos mesmos, procura-se produzir múltiplos efeitos, frente à diversidade de públicos a atender. Com amostras selecionadas que potencializam a validade interna do desenho metodológico da pesquisa avaliativa (em geral, experimental ou quasi-experimental), em detrimento de sua validade externa do público-alvo dos programas e sua representatividade na realidade dura e concreta da implementação de programas em ambientes complexos, geram-se relatórios que, em uma remissão a visões já ultrapassadas acerca da produção do conhecimento científico, se autodeclaram como "politicamente neutros"e "cientificamente atestados". Esquecem-se que a atribuição (ou deslegitimação) dos efeitos identificados em uma população aos componentes de um programa depende de muitas escolhas quanto aos testes estatísticos, níveis de significância, características e tamanho de amostras, dos pressupostos com relação às propriedades de distribuição dos dados. Não se encontra em muitos desses trabalhos a discussão sobre poder estatístico dos testes usados ou sobre a análise de resíduos após a estimação de parâmetros de modelos. Menos ainda comuns são análises mais exaustivas sobre os potenciais vieses introduzidos na estimação do sentido e intensidade do impacto (ou não impacto) pelas calibrações dos grupos tratamento e controle pela técnica propensity score matching.

Com todas essas limitações, advogam que Política Pública"boa"e "científica"é a produzida nos laboratórios de econometria, longe das "escolhas subjetivas" dos gestores 
ou "pressões suspeitas" dos públicos potencialmente favorecidos ou excluídos da "benesse governamental". Tal como um medicamento, Política Pública precisaria passar pelo ensaio epidemiológico típico de caso-controle de laboratório (de econometria, vale acrescentar), crença que segmentos crescentes da comunidade epistêmica de Saúde Pública, envolvida na gestão de programas, deixou de partilhar, pelos insucessos em garantir as mesmas condições contextuais nos grupos de beneficiários e não beneficiários, ou ainda pela complexidade operacional de programas na área e pelas inevitáveis e incontroláveis sinergias advindas de outras políticas ou dos efeitos do contexto socioeconômico, que se manifestam desigualmente pelo território ${ }^{10}$.

Ademais, os randomistas partilham de uma visão ingênua sobre a utilização de avaliações na modificação ou descontinuidade de políticas e programas, como se os resultados dos estudos fossem automaticamente "comprados" e implementáveis rapidamente pelo decisor público. Desconhecem a complexidade do processo de tomada de decisão no setor público e, sobretudo, a engenharia institucional envolvida na operação dos programas. Como bem lembra Weiss em seu livro clássico Evaluation:

Program and policy decisions in a democracy do not take place in an autocratic context. There is rarely a single decision maker who can adopt evaluation results and hand down orders.

(....)

Even when members of the program and policy communities become convinced by the findings and want to take corrective action, they have to generate support in other constituencies, amass resources, allay suspicions, employ staff with appropriate skills, and see that front-line practitioners endorse and implement the changes. (WEISS, 1998, p.324)

Curiosamente, essas limitações metodológicas não enfraquecem a crença dos randomistas quanto à robustez dos achados de suas pesquisas e à superioridade das técnicas que empregam frente a de outras comunidades de avaliadores. Como já advertira Ravaillon (2009) em seu curto ensaio crítico aos randomistas:

From the point of view of development policy-making, the main problem in the randomistas agenda is that they have put their preferred method ahead of the questions that emerge from our knowledge gaps.

\section{(....)}

The emphasis that researchers are now giving to obtaining better knowledge about development effectiveness is welcome. Randomization is one of the tools that can help. However, the important task of investigating what works and what does not in the fight against poverty cannot be monopolized by one method. (RAVAILLON, 2010, p. 2-5)

A "ditadura" do método imposto pelas comunidades epistêmicas a seus membros, no processo de formação dos pesquisadores e de legitimação do conhecimento científico produzido é a grande crítica do clássico - embora pouco lido - livro Contra o Método de Feyerabend (2011). Como bem coloca Araújo sobre uma das polêmicas suscitadas em seu livro: 
... em ciência não deve haver um método rígido a ser imposto, eis que seria um entrave para inúmeras descobertas e avanços científicos. A ciência requer pluralidade de procedimentos metodológicos para lidar com a pluralidade de problemas e situações que a afetam. Para que a ciência progrida, deve ter à sua disposição quantos métodos e procedimentos forem necessários para serem escolhidos e empregados em cada situação específica. (ARAúJO, 2012, p.139)

Criatividade e irreverência foram cruciais para o avanço da Ciência Moderna, como revelou a história da Física de Galileu a Einstein, para citar um campo disciplinar. Assim, Feyerabend adverte:

Especialistas, ou ignorantes que tenham adquirido as insígnias formais de uma especialidade, sempre tentaram - e com frequência tiveram êxito nisso - assegurar para si mesmos direitos exclusivos em domínios especiais. Qualquer crítica da rigidez da Igreja Católica Romana [a Galileu e outros iluministas] também aplica-se a seus sucessores modernos, tanto científicos quanto ligados à ciência". (FEYERABEND, 2011, p.175).

Essas tendências de empiricismo e reificação das técnicas quantitativas não são exclusivas na pesquisa em $M \& A$, mas se replica em comunidades epistêmicas específicas nas Ciências Sociais Aplicadas ${ }^{11}$. O emprego da técnica pela técnica parece estar tomando o lugar, o tempo e o empenho das equipes, em detrimento de análises multidisciplinares e circunstanciadas com que devem ser tratadas as problemáticas complexas que envolvem a produção dos serviços sociais na educação, saúde pública, qualificação profissional ou desenvolvimento social, para citar algumas das áreas mais proeminentes no campo de $M \& A$ no país. A pesquisa na área corre o risco de uma hiperespecialização técnica na investigação das problemáticas que afetam as políticas e programas públicos em detrimento de abordagens mais sistêmicas no entendimento dos mesmos. Alguns centros de pesquisa parecem investir em saber cada vez mais sobre cada vez menos, apostando na ortodoxia clássica do recorte disciplinar dos objetos de análise, decisão que pode ser plausível no mundo acadêmico, mas uma escolha equivocada no universo complexo e interdisciplinar das Políticas Públicas.

Paradigmas e modelos de médio alcance relativamente seguros para garantir produção acadêmica que, por sua vez, gerem resultados que viabilizem premiações, novos financiamentos para pesquisas e formação de quadros é um mecanismo clássico de funcionamento da Ciência contemporânea, de forma mais explícita e estruturada do que Khun (1992) ou que os pesquisadores dos Estudos Sociais da Ciência poderiam imaginar ${ }^{12}$. A diferença - e o problema - é que na área de $M \& A$, como bem observou Worthern et al (2004) em situações assemelhadas e concretas nas políticas educacionais nos Estados Unidos nos anos 1960, essa produção científica com viés sociométrico e/ou economicista acaba muitas vezes sendo aceita de forma pouco crítica ou voluntarista na Administração Pública e, pior, orientando decisões cruciais acerca de mérito, desenho e gestão de programas públicos, mesmo quando a consistência dos resultados são questionáveis ${ }^{13}$. 
Como bem assinalou Porter (1996), o "quantificacionismo" é um instrumento poderoso para tomada de decisão aparentemente imparcial e justa em Políticas Públicas, conferindo autoridade a quem não a conquistou legitimamente pelo voto ou por delegação. Para certas comunidades tecnocráticas e plutocráticas na Administração Pública, as decisões baseadas em dados, indicadores e evidências produzidas em avaliações quantitativas e protocolos estruturados gozam de neutralidade e objetividade incontestáveis. Na realidade, dados e indicadores resultam de uma série de escolhas políticas (sobre que aspectos observar e medir) e preferências metodológicas (sobre como observá-los e medi-los). Nas palavras do autor:

The capacity to yield predictions or policy recommendations that seem to be vindicated by subsequent experience doubtless counts in favor of a method or procedure, but quantitative estimates sometimes are given considerable weight even when nobody defends their validity with real conviction. The appeal of numbers is specially compelling to bureaucratic officials who lack the mandate of popular election, or divine right. (...) A decision made by the numbers (or by explicit rules of some sort) has at least the appearance of being fair and impersonal. (...) Objectivity lends authority to officials who have very little of their own. (PORTER, 1996, p.8).

Aos olhos de pesquisadores de outras comunidades epistêmicas mais plurais no campo de M\&A, a "certeza", a "imparcialidade" e "meta-cientificidade" com que são apresentados as avaliações de políticas e programas produzidos nessa abordagem "quantificacionista" não deixam dúvidas quanto à natureza mítica e dogmática a preceitos positivistas acerca da produção do conhecimento. Mas o campo das Políticas Públicas - e suas subáreas como a M\&A- não pode ser enquadrado como uma Física Social ou uma Microeconomia do Bem-Estar, investigada somente com o arsenal de técnicas de inspiração positivista. Estas ferramentas são insuficientes e limitantes para se entender a complexidade e vastidão em que o campo das Políticas Públicas vem se transformando, um século depois de crescimento sistemático enquanto área de intervenção estatal ${ }^{14}$ e muitos outros enquanto Filosofia Política. Como outras disciplinas científicas que aqui no Brasil demarcam o campo das Ciências Sociais Aplicadas, a produção de conhecimento no "Campo das Públicas" requer, para além das tradições nomológicas-explicativas inspirados na Ciências Naturais, da hermenêutica histórico-interpretativa das Ciências Humanas ${ }^{15}$.

Ademais, o modus operandi da Ciência Moderna, produzida em contexto acadêmico, disciplinar, hierárquico e estável já não é funcional em muitas áreas contemporâneas de conhecimento, muito menos no "Campo das Públicas". Tal como outras áreas dinâmicas de produção de conhecimento, ela vem se reestruturando em bases institucionais e epistemológicas mais amplas como as que Pombo (2006) denomina de Interciências ${ }^{16}$. Não basta "emprestar" conceitos, categorias de análise e paradigmas de outras ciências; é preciso "ressignificá-los" frente aos objetos de análise em questão; é preciso integrá-los na interpretação dos fenômenos e não apenas agregar diferentes perspectivas de análise disciplinar. 
Talvez mais do que uma "Interciência", o "Campo das Públicas" seria, na terminologia emprestada de Echeverría (2009), um ramo exemplar da Tecnociência, com produção de conhecimento fora do laboratório clássico, em contexto transdisciplinar, heterogêneo, heterárquico e instável. Se na Ciência Moderna o conhecimento "válido" precisa ser produzido em laboratório e centros de pesquisa com algum grau de "acreditação" anterior e necessita passar por um ritual controlado de legitimação, assegurado por "pares" acadêmicos em programas de pós-graduação ou em publicações especializadas, na Tecnociência, os estudos, as técnicas e as inovações são gerados - e avalizados - por um número muito maior de agentes, além dos acadêmicos, em circuitos mais plurais e ritos mais descentralizados que os convencionais. Se a Ciência basta a si mesmo em seus conceitos e explicações, a Tecnociência precisa ultrapassá-los em direção à aplicação. O campo de conhecimentos conexos às Políticas Públicas está, pois, mais ligado ao contexto plural e eclético da Tecnociência do que o cartesianismo da Ciência Moderna.

Na Ciência, Interciência ou Tecnociência não existe objetividade absoluta, mas objetividade socialmente construída, como propõe Fourez (1995). Objetividade construída e partilhada pelas comunidades epistêmicas específicas, que demarcam o que é ou não é "científico", o que deve ou não ser observado ou estudado. Nas suas palavras:

Quando se está habituado a ver o mundo de certo modo, torna-se quase impossível ver as coisas de maneira diferente. Questionar essa visão criaria uma profunda crise afetiva. A visão que se tem do mundo surge então como absolutamente objetiva (FOUREZ, 1995, p.55)

Enfim, a Ciência, Interciência ou Tecnociência, e, portanto, as Avaliações de Politicas e Programas têm "partido", e assentam-se em valores e visões partilhadas pelas comunidade científica. E como bem coloca Fourez (1995), a comunidade científica pertence à classe média nas sociedades contemporâneas, identificando-se com a ordem social existente e disputando recursos com outros segmentos e setores da sociedade. Mas reconhecer a natureza humana e idiossincrática da produção de conhecimento não o fragiliza. O que o enfraquece é a falta de transparência metodológica; é a dogmatização de princípios e procedimentos não consensuais; é a tentativa de se apresentarem como neutros e insuspeitos a qualquer prova os resultados de pesquisas quando se sabe que diversas decisões técnicas foram intrinsecamente subjetivas e, de partida, apoiadas em visões e valores de mundo, de Ciência e de Políticas Públicas que não são universais.

\section{Os valores públicos socialmente objetivados nas Avaliações}

Boa parte das diferenças de mérito e resultados de Avaliações de Políticas e Programas decorrem de diferentes recortes do objeto de estudo, do universo de pesquisa e distintas escolhas metodológicas na construção de modelos, indicadores 
e testes. Uma amostra de pesquisa avaliativa com determinadas características selecionadas, um indicador de resultados de um programa que operacionaliza um conceito de determinada forma, a proposição de um certo tipo de teste de hipóteses ou de um certo nível de significância, ainda que respaldados por parágrafos de justificativa metodológica, são escolhas subjetivas que vão produzir resultados em uma ou outra direção.

Mas as questões a investigar e as escolhas metodológicas de como fazê-las refletem, para além das concepções do que se concebe como método científico, os valores públicos e motivações políticas compartilhadas pelos grupos de interesse envolvidos no desenho e avaliação das Políticas Públicas. Esse ambiente é formado por burocratas dos três poderes, dos três âmbitos de governo, especialistas e representantes de segmentos da sociedade - para além de muitos atores - que disputam prioridades, modelos de intervenção e, naturalmente, visões de mundo e de papeis do Estado. Estado Liberal, Estado Regulador e Estado do Bem-estar Social tem desígnios e arquiteturas diferentes de Políticas Públicas, valorizando distintamente a eficiência econômica, eficácia procedural e a efetividade social como critérios de formulação e avaliação da ação pública. São estes os três valores públicos em disputa no desenho, gestão e avaliação de Políticas e Programas Públicos no Brasil contemporâneo, quase trinta anos após a promulgação do "Contrato Social" de 1988 e de sua efetivação ao longo de diferentes governos, em especial, entre 2003 e 2014, com significativa ampliação de escopo e escala de políticas sociais (e, naturalmente, do gasto e controle público). Ainda que todos sejam valores republicanos intrínsecos às sociedades democráticas, a primazia de um sobre os demais está condicionada à concepção subjacente de Justiça Social e a forma de alcançá-la; por sua vez tal concepção aponta o modelo de avaliação a ser empregado que, ao final, traz evidências que reforçam ou não as visões de mundo e as escolhas de políticas públicas realizadas (Figura 1).

Figura 1: O ciclo determinista da Concepção de Estado e tipo de Avaliação

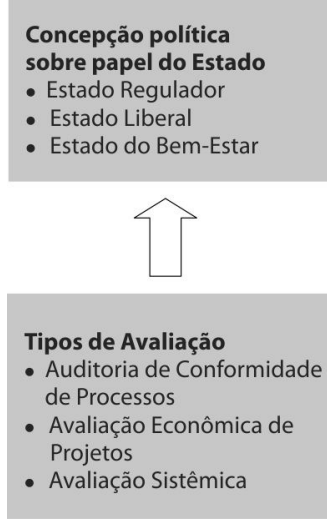

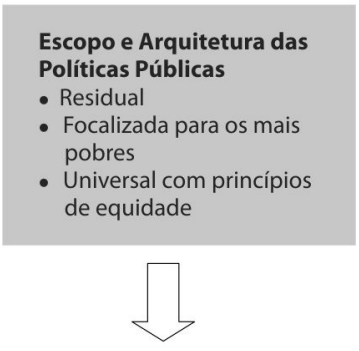

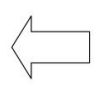

Valor Público da Avaliação

- Eficácia Procedimental

- Eficiência Econômica

- Efetividade Social 
Antes de avançar na discussão, ou melhor, na argumentação - dedutiva - de como tipos de avaliação se vinculam a concepções de Estado e de Políticas Públicas, cabe uma advertência: todo esforço de sistematização de ideias e conceitos em categorias específicas sempre está sujeito a questionamentos sobre a consistência, pureza e exaustividade dos tipos ideais construídos. A realidade é sempre mais complexa do que é possível apreender e enquadrar em modelos mais abstratos e tipologias mais sintéticas. Mas estes ajudam a explicitar mais claramente as principais dimensões em jogo. Na Ciência e na Tecnociência, operações de síntese ensaística e abstrações conceituais requerem esforços de investigação empírica e reflexão analítica. A construção de tipologias é uma dessas operações.

Eficiência Econômica é o valor primaz a ser considerado no desenho e avaliação de Políticas e Programas Públicos na perspectiva daqueles que advogam por um Estado menos protagonista. É o domínio do Estado Liberal, justificado a partir de conceitos e tradições de pesquisa da Teoria da Escolha Racional (HOWLETT et al, 2013). No que interessa discutir nesse texto, a prescrição normativa advogada por esta escola de pensamento - e em suas variações mais ortodoxas e liberais - de que a atividade estatal deve ser limitada ao máximo possível, garantindo todo protagonismo aos mercados, determina, ex-ante, os resultados a que chegam os estudos avaliativos de Políticas Públicas nela inspirados. Nessa visão, equidade social não é o valor que orienta a Política Pública ou seu julgamento, mas sim a eficiência econômica no uso dos recursos "subtraídos do mercado". Cobertura e equidade de acesso, efetividade e coesão social, valores caros à constituição de políticas públicas em Estados de BemEstar Social não são critérios ou parâmetros de avaliação, pois o que está em questão é a própria legitimidade do Estado em atuar em áreas em que o Mercado poderia deveria prevalecer. Afinal, o mercado seria mais eficiente que o Estado em quase todo tipo de oferta de serviços, com exceção dos genuinamente públicos e não competitivos.

Nesse contexto, a Justiça Social seria aquela passível de ser produzida pelo mercado, segundo uma "ética de responsabilidade", premiando as escolhas eficientes (meritórias) e punindo aquelas ineficientes (e irresponsáveis). A busca pela eficiência seria, afinal, o mecanismo de redistribuição de bem-estar, por meio das oportunidades no trabalho:

Ademais, argumenta-se que a própria eficiência econômica se beneficiaria das desigualdades, o que acabaria por favorecer os mais pobres: as remunerações desiguais funcionariam como incentivos ao trabalho e à poupança, induzindo re-alocações de recursos promotoras de eficiência; uma maior eficiência econômica, dinamicamente, se traduziria em crescimento econômico, então em emprego e renda, estendendo vantagens também aos menos favorecidos. (KERSTENETZKY, 2006, p.566)

No Estado Liberal, a política social é um mecanismo de compensação ou correção das falhas de mercado e projetos sociais são desenhados para atender às necessidades da população mais pobre, sem recursos para compra de serviços educacionais, de 
saúde, de qualificação profissional junto aos agentes privados ofertantes. Assim a implementação dos projetos sociais financiados com recursos públicos deve seguir um desenho operacional que facilite sua avaliação ao longo do tempo, produzindo indicadores que identifiquem os agentes mais eficientes na geração do impacto desejado. O arranjo operacional da Política é, nesse caso, em formato de rede capilarizada de prestadores de serviços, com um só nó, no centro onde se situa o gestor dos contratos, que dispõe de recursos e incentivos para induzir a oferta segundo os parâmetros planejados no escritório (de programação orçamentária). Como o objetivo é, no médio e longo prazos, selecionar os projetos sociais - e os operadores - mais bemsucedidos, emulando a lógica de mercado (só sobrevivem os mais eficientes e eficazes), os indicadores de interesse são os que fornecem parâmetros de eficiência dos gastos na produção dos serviços e os que medem a intensidade do desempenho individual do beneficiário atendido (caso) versus o não atendido (controle), preferencialmente junto ao mercado.

As avaliações conduzidas nesse contexto são do tipo de estudos do que se denominou, em oportunidade anterior (JANNUZZI 2016b), de Avaliação Econômica de Projetos Sociais. Para as comunidades epistêmicas e de práticas envolvidas especialmente econometristas e servidores públicos da área fazendária - esses estudos tomam forma como avaliações experimentais e quasi-experimentais, seja na apreciação prévia de projetos sociais, como uma "prova de conceito", ou na avaliação somativa, como validação de mérito da ação social ${ }^{17}$. Nessa linha de estudos, é preciso garantir, pelo desenho da avaliação, se os resultados e impactos decorrem da intervenção social, isto é, é fundamental identificar a atribuição de causalidade e a contribuição marginal do projeto, menos talvez, que a própria intensidade ou pluralidade dos impactos. Se eficiência econômica é o "valor político" subjacente à avaliação da Política Pública, a estética da formulação matemática, complexidade da técnica, validade interna do estudo e precisão potencial das estimativas são os "valores epistemológicos" que consagram a "cientificidade" dos resultados a que chegam, às expensas do que se poderia arguir quanto à consistência substantiva do modelo analítico adotado, validade externa do estudo ou riqueza analítica para responder às questões demandadas pelos gestores de políticas e programas. É a operacionalização mais acabada da abordagem Evidence-based Policy Making: ao fim e ao cabo, o que interessa são os indicadores de custos e impactos, apurados nos dois extremos da cadeia de implementação de uma política ou programa (Figura 2).

Não há Política ou Programa Social que saia incólume - invariavelmente deslegitimados - nessa perspectiva de estudo de Avaliação em que a primazia da Eficiência Econômica é o valor político de julgamento público. Se é fato que o veredicto final apoia-se nas evidências, provas e testes preparados no "imparcial e técnico" laboratório de econometria, as políticas e programas já estavam condenadas, de partida, pela negação da função social do Estado e da Política Pública universal. Se já há problemas de legitimidade e mérito de políticas sociais mais abrangentes nessa concepção de 
Estado, menos ainda se sustentam propostas de políticas no campo ambiental ou cultural. Enfim, não há como produzir evidências alternativas que consigam livrar a Política Pública do confinamento minimalista que o Estado Liberal a submete.

Figura 2: Tipos de Avaliação e ênfases investigativas nas fases de implementação de programas

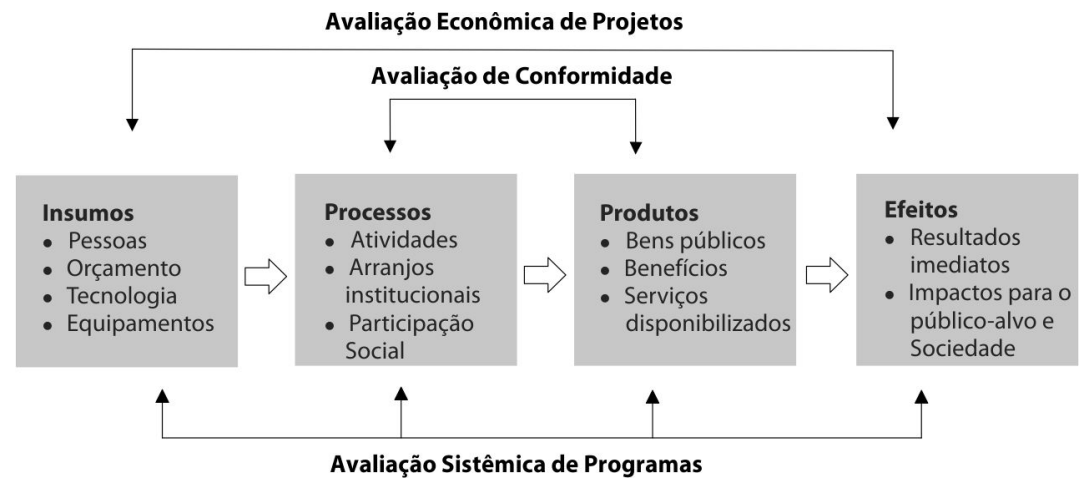

Conformidade Procedimental é o valor público explícito que orienta outra linha de estudos avaliativos, ou melhor, as Auditorias de Conformidade (ou Compliance), aqui entendidos como os resultados de auditorias, apreciações, pareceres e recomendações acerca de políticas e programas públicos realizados no âmbito dos órgãos de controle e Sistema de Justiça ${ }^{18}$. No documento em que o Tribunal de Contas da União normatiza os "Padrões de Auditoria de Conformidade" preconiza-se que o relatório final de auditoria zele pelos atributos sintetizados pelo sugestivo acrônimo C.E.R.T.O. (Clareza, Concisão, Convicção, Exatidão, Relevância, Tempestividade e Objetividade). Se o acrônimo já, de partida, enaltece o valor público a ser perseguido - a perfeição do ato administrativo - o detalhamento dos atributos não dá margem para qualquer dúvida quanto à busca por uma avaliação inconteste, objetiva, insuperável e exata a ser defendida em um "tribunal". Quanto à Exatidão, a avaliação registrada pelo auditor deve :

Apresentar as necessárias evidências para sustentar seus achados, conclusões e propostas, procurando não deixar espaço para contra-argumentações. A exatidão é necessária para assegurar ao leitor que o que foi relatado é fidedigno e confiável. Um erro pode pôr em dúvida a validade de todo o relatório e pode desviar a atenção da substância do que se quer comunicar. As evidências relatadas devem demonstrar a justeza e a razoabilidade dos fatos descritos. Retratar corretamente significa descrever com exatidão o alcance e a metodologia, e apresentar os achados e as conclusões de uma forma coerente com o escopo da fiscalização. (TCU 2010a, p.10).

Ainda que necessária em qualquer perspectiva de atuação do Estado, a Auditoria de Conformidade é o tipo de avaliação predominante em situações em que o Estado é entendido como Regulador, Gendarme ou ainda, em uma versão mais moderna como propôs a Nova Administração Pública - Estado Gerencial. Não há como não 
remeter tal concepção às experiências históricas das monarquias parlamentares do século XIX, pela crença do Direito como promotor de ordem e progresso e pelo escopo limitado das políticas públicas. Nesse caso, a educação básica constitui o principal campo legitimado de intervenção pública, com acesso e progressão condicionados ao desempenho individual do usuário dos serviços, especialmente às séries superiores ou ao ensino técnico. Saúde pública pode também ser outra área de ação estatal, mas com cunho marcadamente higienista, com campanhas de vacinação pública e de saneamento urbano.

Em um Estado Regulador, em que a principal função é zelar pelo cumprimento de contratos individuais, a avaliação centra-se no exame da regularidade normativa na prestação dos serviços e qualidade dos produtos, a partir de um protocolo de auditoria padrão, já que a política é implementada mediante contratos de gestão com todas normas operacionais definidas, em tese, anteriormente. Políticas sociais são entendidas como sistemas fechados, operados como organizações burocráticas hierarquizadas, com controle centralizado no governo e em que as normas são suficientes para estabelecer comportamentos dos agentes prestadores de serviços e também dos beneficiários. Não se cumprindo o estabelecido, novas e específicas determinações emanadas de juízes, tribunais e órgão de controle cuidariam para "colocar em ordem" as Políticas Públicas ${ }^{19}$. Em um Estado unitário, com oferta de serviços públicos bastante residual é possível que uma plutocracia competente consiga antecipar as normas necessárias para que as políticas e programas assim funcionem.

Em contextos em que Políticas Públicas operam em ambiente descentralizados, fragmentados e heterogêneos, como é o caso brasileiro, o ativismo regulamentador dos Sistemas de Justiça e de Controle Público não parecem promover justiça social e protegem o patrimônio público em médio e longo prazos. A visão normativa-positiva acerca do funcionamento do Estado e da Sociedade partilhada pelos operadores do Direito e outras comunidades burocráticas prevalentes nesse contexto (como Contadores, Administradores e outras formações nas Ciências Duras) podem induzir decisões monocráticas, por vezes ingênuas ou voluntaristas, que minam acordos, pactuações e entendimentos alinhados entre inúmeros agentes públicos, em fóruns continuados de discussão republicana.

Como observa Sarmento (2011), a constitucionalização dos direitos sociais empoderou o Judiciário, chamado por diferentes atores a buscar solução de questões polêmicas e conflitivas na sociedade. O princípio clássico de separação de poderes cede lugar, nessa nova interpretação do papel do Judiciário, a visões mais favoráveis ao ativismo judicial em defesa dos valores constitucionais. Ademais, os vinte anos de governo militar - em que Atos Institucionais se inspiravam em princípios revolucionários não claramente explicitados, acima dos preceitos constitucionais - deu margem na Assembleia Constituinte para o fortalecimento de outros mecanismos de controle político, jurídico e administrativo (Ministério Público, Tribunal de Contas, Advocacia Geral da União), assim como para acesso à justiça (Defensoria Pública). Esse foi o 
ambiente propício para florescimento da judicialização da política nos anos seguintes, como bem apontou Valle (2011), criando expectativas exacerbadas de seu potencial realizador. Nas suas palavras:

O contexto histórico de enunciação da Carta de 1988 evidencia um encantamento com o caráter transformador do compromisso com os direitos fundamentais e uma aposta na aptidão do Poder Judiciário para figurar como garantidor desse projeto. Essa mesma crença se põe hoje à prova, com uma crescente transferência ao Judiciário das expectativas de concretização do ideário de transformação social que se continha e contém no elenco de direitos fundamentais (sempre crescente) contemplados no Texto de Base. (VALLE, 2011: 16).

Também não há como uma Política ou Programa Social não sair repreendida desfigurada e no limite, inviabilizada- nessa perspectiva de Rules-dictated Policy Making. No tribunal da Auditoria de Conformidade as narrativas "precisas" e "incontestes" apoiam-se em evidências certamente fartas do descumprimento dos protocolos na execução dos serviços e entrega dos produtos de Políticas e Programas, em geral, motivados pela proatividade bem intencionada - por vezes descuidada- do técnico ou gestor do programa. Afinal, a clarividência do formulador-contratante é insuficiente para antecipar a miríade de problemas quando da implementação dos programas e menos ainda, de prescrever normativamente toda a cadeia de procedimentos a serem seguidos. Se é fato que as recomendações e determinações advindos das auditorias e decisões judiciais podem proteger o patrimônio público e o interesse individual não atendido, também podem enfraquecer o impacto coletivo, a tempestividade esperada e engajamento técnico e institucional necessários à concretização da ação pública ${ }^{20}$.

Eficiência e legalidade administrativa no uso de recursos públicos são, certamente, princípios importantes na gestão - e avaliação - das Políticas Públicas. Constituemse em critérios-meio, técnicos e administrativos, para alcance de um designo político socialmente desejado. Afinal, políticas e programas são propostos e desenhados para atender uma demanda social alçada à agenda prioritária de Estado ou governo. Mas a qualidade do gasto e conformidade burocrática não podem ser o critério central de julgamento de mérito das Políticas Públicas, muito menos em países ou Estados em que o acesso a direitos humanos, justiça social e melhoria do bem-estar são valores constitucionais e fundantes da ação pública. Assim, na perspectiva de construção de um Estado com maior protagonismo no campo social, a Efetividade Social é o valor máximo buscado no desenho e avaliação de Políticas e Programas. Nesse contexto, políticas e programas públicos são criados para garantir direitos sociais e melhores condições de vida ao cidadão, bem como maior justiça e coesão social para a sociedade, valendo-se, para tanto, dos desenhos operacionais e arranjos de implementação mais efetivos, considerando a complexidade da intervenção, capacidade de gestão de agentes públicos e privados e necessidades específicas de públicos-alvo segundo sua maior ou menor vulnerabilidade. Políticas e programas sociais não são bens e serviços comuns produzidos por empresas e consumidos por indivíduos como em 
um mercado "racional" de trocas, mas formulados e moldados segundo interação de diversas instituições, agentes e percursos históricos (HOWLETT et al, 2013).

Políticas Públicas orientadas à busca da equidade são constitutivas do Estado de Bem-Estar Social. Na sua realização histórica mais acabada, nesse contexto conjugamse políticas de proteção social a riscos individuais - na saúde, previdência e assistencial social (combinadas com políticas de promoção de capacidades) na educação, trabalho, inclusão produtiva - e ações afirmativas para equidade de etnia, gênero e origem social. Trata-se de um modelo de Estado inspirado na experiência história da Europa Continental e Nórdica, muito distinto do modelo americano de individualização do risco social ou da inexistência ou precariedade de mecanismos de proteção social que possam deslocar recursos públicos e privados para outras atividades que não o crescimento econômico, como na China e países do sudeste asiático (MORENO et al., 2014, p. 99). Nesse contexto, as Políticas Públicas originam-se legitimadas pela sociedade e seu Contrato Social. Requerem, naturalmente, gestão eficiente de recursos e "auditabilidade" de procedimentos, mas a legitimidade das Políticas se reafirma por sua capacidade de provocar as mudanças sociais desejadas. É preciso garantir, pois, os meios de sua pela efetivação.

A avaliação de Políticas e Programas requer, nesse sentido, uma abordagem sistêmica, em que se produz informações para todas as etapas da implementação das políticas e programas, investigando seus componentes sistêmicos como as estruturas técnicas-administrativas e político-relacionais: recursos humanos, recursos financeiros, equipamentos, serviços disponíveis, participação social e institucionalidades do arranjo operacional do programa (Figura 3). Subentende o envolvimento de equipes multidisciplinares, compostas por técnicos envolvidos diretamente com as políticas e especialistas externos, com uma abordagem multimétodos de pesquisas de avaliação, crença na natureza contingencial do conhecimento técnico-científico e reconhecimento da perspectiva técnico-política da decisão em políticas públicas (SAGI, 2016). Nesse sentido, também são úteis os protocolos de Auditoria de Conformidade e as metodologias estruturadas da Avaliação Econômica de Projetos. Mas não se trata de analisar aspectos relacionados somente a Impactos frente a Insumos ou Produtos e Processos, mas levantar informações que contribuam para a implementação das políticas e programas, de modo que as mesmas cumpram os propósitos para os quais foram guindadas à agenda.

A Avaliação Sistêmica aqui proposta guarda muitas similaridades com o modelo proposto por Minayio et al (2005), denominada Avaliação por Triangulação de Métodos. Trata-se, na proposta das autoras,

de uma dinâmica de investigação e de trabalho que integra a análise de estruturas, dos processos e dos resultados, a compreensão das relações envolvidas na implementação das ações e a visão que atores diferenciados constroem sobre todo o projeto...[valendo-se da]combinação e cruzamento de múltiplos pontos de vista, a tarefa conjunta de pesquisadores com formação diferenciada, a visão de vários 
informantes e o emprego de uma variedade de técnicas de coleta de dados que acompanha o trabalho de investigação (MINAYIO et al 2005, p.29).

Assim, a Avaliação Sistêmica é um processo de aprendizado organizacional para políticas sociais, plural em perspectiva metodológica, contrapondo-se às soluções um tanto ingênuas ou simplificadoras prometidas pelo "normativismo" burocrático das auditorias de conformidade ou pelo "positivismo" tecnocrático dos exercícios econométricos de avaliação de projetos sociais. Para além da eficiência econômica e conformidade procedimental da ação pública, a Avaliação Sistêmica se pauta por um conjunto mais amplo de valores e princípios da atuação do Estado, como cobertura e equidade de acesso a diferentes públicos, qualidade dos serviços e contribuição para promoção de acesso a direitos sociais, redução da desigualdade e maior coesão social. Tais dimensões acabam por fortalecer a legitimidade social das políticas, assegurada, de partida, pela legitimidade política que Estados republicanos garantem aos governos eleitos e suas escolhas de agendas prioritárias.

Figura 3: Os componentes das Avaliações Sistêmicas de Políticas e Programas

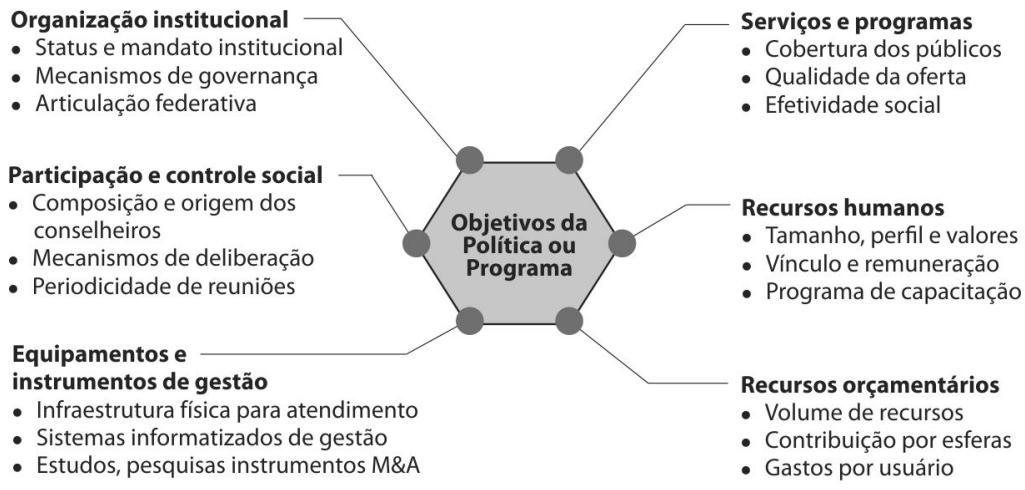

\section{Considerações fincis}

Embora os manuais aplicados na área, sobretudo os disseminados por organizações multilaterais de fomento, dediquem-se em apresentar as etapas, métodos e técnicas de monitoramento e avaliação como se fossem universais, neutros, livres de uma concepção ideológica e política fundante, as práticas na área estão longe de assim se revelarem. Como se procurou discutir nesse texto, encarada como subcampo da Interciência ou da Tecnociência, a Avaliação é sim uma atividade influenciada por valores humanos, políticos e ideológicos (VAITSMAN \& PAES-SOUSA, 2009). Se o desenho e a implementação de políticas e programas são construções políticas por que não a Avaliação não o seria? Afinal.... 
... the policies and programs with which evaluation deals are the creatures of political decisions. They were proposed, defined, debated, enacted, and funded through political processes and in implementation they remain subject to pressures - both supportive and hostile - that arise out of the play of politics.

The programs with which the evaluator deals are not neutral, antiseptic, laboratory-type entities. They emerged from the rough and tumble of political support, opposition and bargaining. (WEISS, 1993, p.94)

Avaliação não é uma investigação neutra com respeito aos valores de quem a realiza, seja ele o formulador comprometido com a criação da política; seja um pesquisador externo ou instituição contratada (YANES, 2009). A narrativa dos resultados da avaliação depende, como se procurou argumentar nesse texto, dos valores imanentes das Políticas Públicas. Na mesma linha, advoga Uitto (2014) em defesa da Sustentabilidade Ambiental como mais um valor público a ser considerado na avaliação de políticas e programas:

Although one role of evaluation is to generate the most objective and verifiable data and information as possible for decision-making, evaluation is a societal function that must be anchored in the values and goals that we hold. Evaluation should be guided by moral principles and understanding the underlying processes, nor just measuring outcomes (Rallis apud Uitto 2014,p.8).

Assim, no debate sobre impactos ou não das políticas e programas, o que está em disputa é muito mais que a validade interna do método e a robustez do teste estatístico produzido no laboratório ou a validade externa e riqueza analítica dos achados empíricos em estratégias multimétodos de investigação. O que está em disputa é muito mais que a objetividade absoluta ou objetividade socialmente construída do conhecimento técnico-científico, contrapondo positivistas e pós-positivistas ${ }^{21}$. Na realidade, o que está em disputa nas avaliações são visões político-ideológicas sobre Estado e natureza das Políticas Públicas, relevadas pela escolhas de que valores expressam os fins (e os meios) da ação pública: a eficiência do gasto público frente a outros usos que o mercado poderia fazer do mesmo; a eficácia no cumprimento do rito legal dos procedimentos técnico-burocráticos programados frente a escolhas discricionárias socialmente legítimas ou a efetividade social advinda da operação pactuada e legitimada das políticas públicas (Figura 4 e Quadro 1).

Avançar na perspectiva de estudos em Economia Política da Avaliação ou Estudos Sociais da Avaliação é certamente necessário no país. Poderão contribuir para uma abordagem ética e epistemológica mais transparente para os Estudos de Avaliação ou, lato sensu, para o "Campo das Públicas", ao explicitar os "valores subjacentes às avaliações". Isso é fundamental em um momento em que se estão tomando decisões cruciais sobre desenho, cobertura e a própria existência de Políticas e Programas Sociais no Brasil ${ }^{22}$. 
Figura 4: Valores públicos para Avaliação e das Políticas e Programas

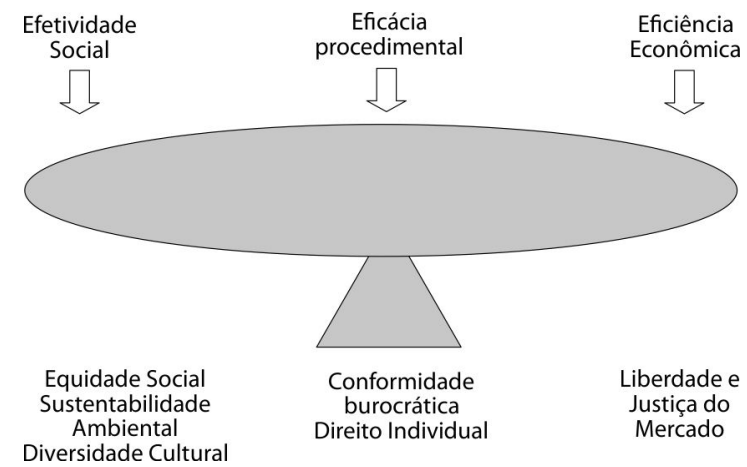

Como ilustra Latour (2000), já são conhecidas, de longa data, as estratégias retóricas de sustentação de procedimentos e achados na produção científica nos laboratórios e centros de pesquisa ${ }^{23}$. De fato, a leitura de várias avaliações e estudos aplicados à análise de políticas no país revela algumas delas: a busca do argumento de autoridade pela citação de bibliografia clássica ou, cada vez mais, de pesquisadores e seus orientados de um centro ou universidade com forte financiamento externo; a matematização dos procedimentos e a dedução lógica dos resultados; a discricionariedade na escolha de amostras, construção de indicadores, tipos de testes de hipóteses e de níveis de significância; e por fim, mas não menos frequente, a adoção de hipóteses "heroicas" e/ ou supostos ceteris paribus no começo da pesquisa (e explicitados no meio do relatório final), mas esquecidos quando da apresentação das conclusões.

A discussão sobre os valores públicos que orientam as avaliações de políticas e programas também é um debate necessário frente aos problemas, já de algum tempo, da gestão da Política Social frente à escalada da judicialização das demandas individuais e das determinações operacionais ditadas pelos Tribunais e Órgãos de Controle. Decisões e determinações externas, com a especificidade com que são registradas, encaminhadas para cumprimento tempestivo com pouca ou nenhuma margem discricionária do gestor encarregado das políticas e programas públicos acabam por desfigurá-las ou por criar disfuncionalidades que, ao fim e ao cabo, conspiram contra os impactos sociais mais gerais esperados pela sociedade ${ }^{24}$. Sem negar a necessária publicidade, regularidade e oficialidade de qualquer ato administrativo na gestão de programa, seria a compliance e a diligência burocrática os critérios de avaliação de empreitadas complexas como são as políticas e programas?

Sem negar a importância de princípios como eficiência econômica e conformidade procedural na gestão de políticas e programas, é a efetividade social o valor público fundamental a orientar a avaliação das Políticas Públicas. Eficiência e conformidade são critérios-meios, aplicáveis à processos e atividades, não valores-finalísticos 
das Políticas. Devem estar presentes, sobretudo, no desenho e desenvolvimento de processos, assegurando continuidade de recursos orçamentários e base legal para operação de políticas e programas. Na perspectiva de formulação de Políticas Públicas orientadas à Equidade (Equity-guided Policy Making), como propugnado pela Constituição de 1988 e diversos outros documentos normativos vigentes que estabelecem Políticas Nacionais e Tratados Internacionais, valores como equidade, justiça, bem-estar social e, em tempo, sustentabilidade ambiental são o critérios finalísticos a inspirar as Avaliações: Avaliação como processo - não como etapa - de aprendizagem organizacional e aprimoramento da gestão e desenho das políticas e programas com efetividade social; Avaliação produzida a partir de uma abordagem sistêmica do processo de implementação de políticas e programas que produzam as mudanças sociais desejadas.

Não existe uma iluminada Evidence-based ou ilustrada Rules-dictated Policy Making. Existem Políticas Públicas orientadas por Valores. Dependendo do Contrato Social firmado entre Estado e Sociedade, as Políticas Públicas estão inspiradas em valores mais afetos à ética da responsabilidade e mérito individual em princípios de igualdade, solidariedade, coesão social, sustentabilidade ambiental, preservação e fomento da diversidade cultural. Desses valores derivam concepções mais tecnocráticas, plutocráticas ou democráticas no desenho, gestão e avaliação das políticas. 


\begin{tabular}{|c|c|c|c|}
\hline 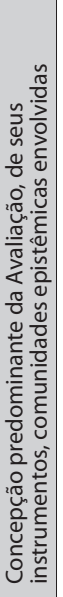 & 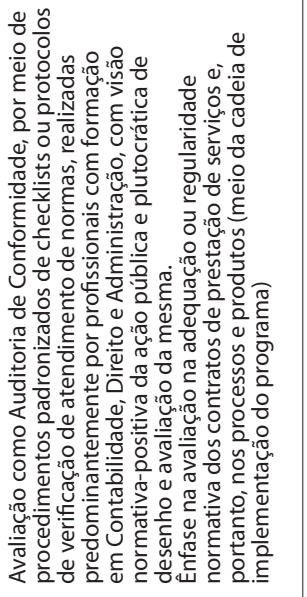 & 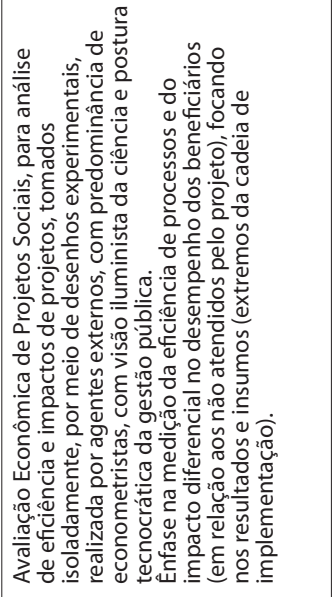 & 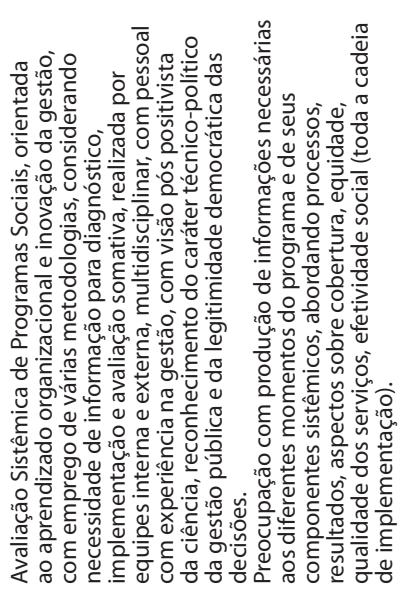 \\
\hline 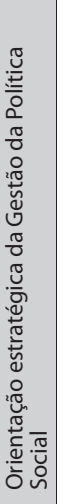 & 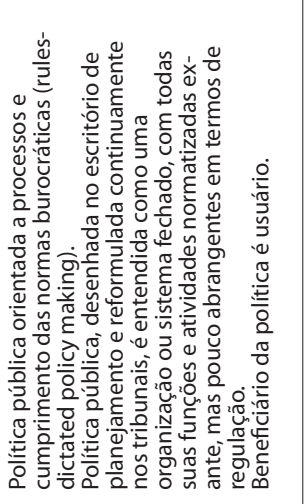 & 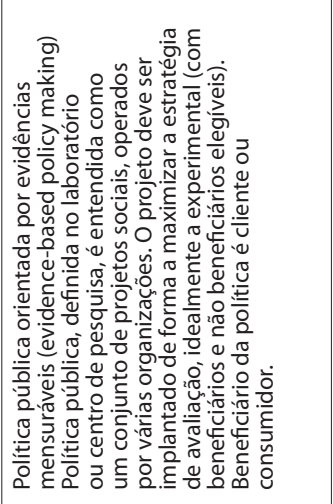 & 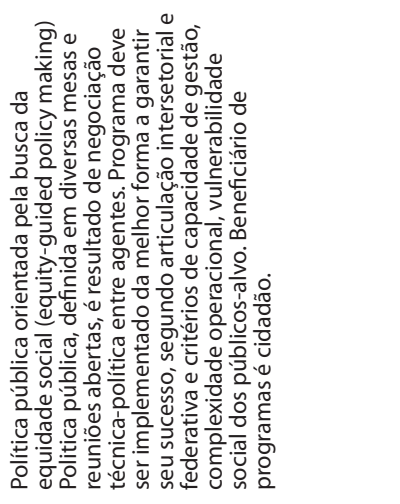 \\
\hline 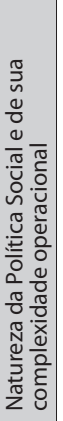 & 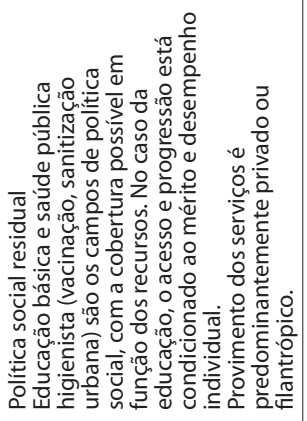 & 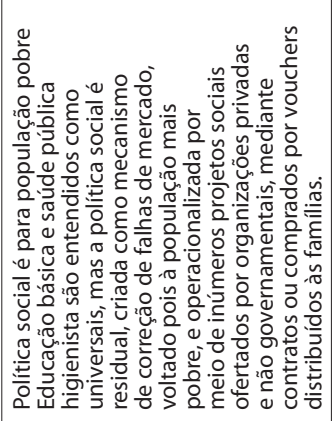 & 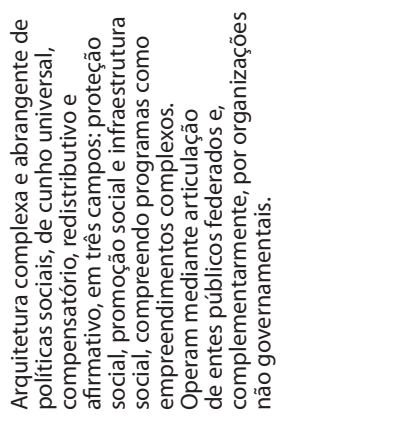 \\
\hline 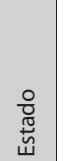 & 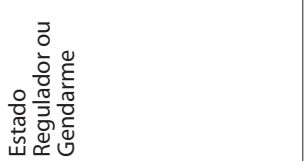 & 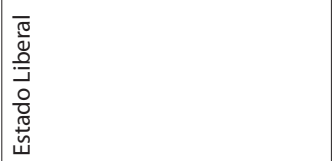 & 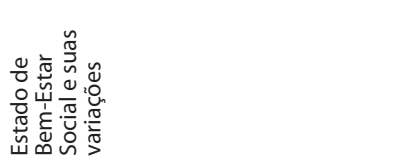 \\
\hline
\end{tabular}




\section{Notas}

'As ideias apresentadas nesse texto devem-se, em boa medida, às discussões sobre temáticas de avaliação com Alcides Gussi, Tereza Campello, Paula Montagner, Aline Hellmann, Marcia Joppert, Luciana de Sousa Leão e muitos colegas de trabalho na Secretaria de Avaliação e Gestão da Informação, especialmente quando da elaboração do livro "SAGI: informações e conhecimentos para as Políticas de Desenvolvimento Social" (SAGl 2016) - disponível em https://drive.google.com/file/d/OBOrv-8MCU4JdQk9HWkVFc1B2bjQ/ view?usp=sharing - e durante período de Licença Capacitação no Instituto de Ciência Política da Universidade de Brasília e na Escola Nacional de Administração Pública entre junho e novembro de 2016. Não Ihes cabe nenhuma responsabilidade sobre o conteúdo, omissões, interpretações e eventuais equívocos do autor.

2 Evidence-based Policy Making designa um conjunto de práticas e conhecimentos relacionados ao ideário da Gestão por Resultados propugnado pela Nova Administração Pública, com fortes implicações no campo de $M \& A$, como discutido mais à frente nesse texto, a partir do manual de Avaliação de Impacto disseminado pelo Banco Mundial (GERTLER et al, 2015).

3 Rules-dictated Policy Making é um termo aqui criado para denominar o conjunto de práticas e conhecimentos - e procedimentos deles decorrentes - advindo dos trabalhos de auditorias de programas realizadas pelos órgãos de controle, assim como as inúmeras e também crescentes decisões do Sistema de Justiça (juízes e promotores) acerca da forma de operação, públicos-alvo a atender e até dos objetivos das políticas e programas. Para além de evidências, a prática de Policy Making nesse contexto se caracteriza por produzir determinações a serem cumpridas sem margem de discricionariedade do gestor responsável pela política ou programa (daí o uso do termo Rules-dictated). Se é fato que os mecanismos para tanto já estavam previstos na Constituição de 1988, é o contexto de fortalecimento das Políticas Sociais, de advocacy de direitos de minorias e de expansão de recursos orçamentários e de pessoal do Ministério Público, Tribunais e Órgão de Controle, pós-2003, que dão concretude a essa perspectiva de "formulação de política pública" (daí o termo recente). O anglicismo é proposital: não será por falta dele que se deixará de marcar posição.

${ }^{4}$ Vale citar ainda, como documentos que explicitam compromissos de justiça, equidade e bem-estar social no Brasil- e, portanto, apontam valores, princípios e parâmetros para análise e avaliação das Políticas Públicas-, os Estatutos da Criança e Adolescentes, do Idoso, a Declaração do Milênio, a Agenda dos Objetivos de Desenvolvimento Sustentável, a Convenção de Combate ao Trabalho Infantil e o memorando de intenções de combate ao Trabalho Precário.

${ }^{5} \mathrm{O}$ anglicismo aqui também é proposital. Não se pode deixar de reconhecer que, infelizmente, na disputa por legitimidade no mercado de conhecimento tecnocientífico contemporâneo, textos e termos em inglês saem na frente. Assim, para aqueles que assim valorizam o conhecimento em Políticas Públicas, não será por falta de terminologia pretensiosa que a Política Pública guiada por princípios de equidade ficará atrás das demais abordagens.

${ }^{6}$ Nesse relatório, produzido por agência de avaliação independente das Nações Unidas, há diversas críticas aos Relatórios de Desenvolvimento Humanos produzidos desde 1990 e, em particular, a "autonomização" do Índice de Desenvolvimento Humano e sua "centralidade" nas discussões suscitadas pela divulgação anual dos relatórios, muitas vezes empobrecendo o debate sobre o que é, de fato, relevante para o Desenvolvimento Social, Crescimento Econômico e Proteção Ambiental (a concepção mais atual de Desenvolvimento pelas agências das Nações Unidas).

${ }^{7}$ Isso é claro no campo educacional. A criação, pelo INEP, dos testes de avaliação de desempenho do Sistema de Avaliação da Educação Básica (SAEB) e a introdução posterior do Índice de Desenvolvimento da Educação Básica como medida de avaliação da "performance educacional" acabou provocando, inclusive, uma "febre de avaliação" com criação de testes de desempenho por secretarias estaduais e municipais de educação. Mais recentemente o INEP resgatou a importância de uma visão mais sistêmica do processo educacional, como revela a proposição do Sistema Nacional de Avaliação da Educação Básica (SINAEB), em que medidas de desempenho escolar compõe parte de uma matriz mais ampla e rica de indicadores educacionais.

${ }^{8}$ Nas suas palavras "Por desgracia, muchos interesados, a distintos niveles, creen que se puede (y se debe) realizar evaluaciones de impacto de manera rutinaria a todos los programas. Paradojicamente, esa insistência en tratar de realizar evaluaciones de impacto de manera sistematica, puede conducir al resultado no deseado de desperdiciar recursos (que son limitados) por tratar de realizar uma evaluacion de este tipo." (MORAL-ARCE, 2014, p.40).

${ }^{9}$ Martin Ravallion foi economista-chefe do Banco Mundial durante muitos anos, tendo publicado diversos artigos no campo da pobreza. Escreveu o texto "Should randomists rule?" em 2010, fazendo uma crítica às crenças e abusos na utilização dos métodos experimentais na avaliação de programas públicos e na tomada de decisão em políticas. Daí sua aludida "insuspeição". 
${ }^{10}$ Uma análise mais extensa sobre os "mitos" da avaliação experimental pode ser consultada em Ravallion (2009), Moral-Arce (2014) e Jannuzzi (2016a).

11 O primado das "estatísticas neutras" ou das "interpretações dos indicadores" na Economia foi tema de um interessante debate no jornal Folha de S.Paulo em 21 e 24 de agosto de 2016 entre, do lado positiva-ortodoxo-liberal, Samuel Pessoa e Marcos Lisboa, e do outro, plural-heterodoxo-estruturalista, Elias Jabbour e Luis Fernando de Paula.

${ }^{12}$ Essas visões idealísticas e positivistas da Ciência partilhadas na comunidade de pesquisadores das Ciências Sociais Aplicadas, depois de mais de cinquenta anos da "denúncia"khuniana da natureza humana e idiossincrática da produção do conhecimento científico e do acervo dos Estudos Sociais da Ciência é revelador de um problema muito grave na ementa dos cursos de Epistemologia ou Metodologia da Ciência nos cursos de graduação e pós-graduação.

${ }^{13}$ No Brasil, o Pronatec - Programa Nacional de Acesso ao Ensino Técnico e ao Emprego- operado entre 2011 e 2015, é um bom exemplo de como um programa com uma série de méritos (JANNUZZI, 2016a) pode ser descontinuado por avaliações instrumentalizadas por esse viés sociométrico-economicistaliberal (BARBOSA Fo. et al, 2015).

${ }^{14}$ Até início do século XX, os gastos com financiamento das atividades estatais mantinham-se por volta de $7 \%$ do Produto Interno Bruto nos diferentes países europeus. Com o ativismo operário, guerras e a instabilidade econômica os Estados passaram a ter um papel não apenas regulador, mas intervencionista no campo econômico e social. Assim, nos anos dourados do capitalismo, no pós-guerra, a necessidade de financiamento dos Estados de países europeus para promoção das Políticas Públicas (na forma de isenções ou programas) já estava além dos 30\%, cifra que o Brasil só chegou, e estabilizou, nos anos 2000.

${ }^{15}$ Estas são as duas categorias ou tradições de pesquisa que Habermas (2009) insiste em pontuar, a despeito da negação do cientificismo da última pelos positivistas.

${ }^{16}$ Para a autora, Ecologia e Neurolinguística seriam exemplos de Interciências. Para além dessas categorias em que o conhecimento científico contemporâneo se desenvolve mais rapidamente, ela propõe ainda as Interdisciplinas como a Sociologia das Organizações e Pesquisa Operacional e as já mais conhecidas Ciências de Fronteira, como a Geografia Econômica e Engenharia Genética (POMBO, 2006).

${ }^{17}$ É bem verdade que existem outras metodologias empregadas, para além dos experimentos, como o revelam os trabalhos valorizados no Prêmio de Qualidade do Gasto Público. Mas todos compartilham a mesma preocupação: "estaria o recurso público sendo usado de forma mais eficiente que aquela que mercado poderia em tese proporcionar?"

${ }^{18}$ Em Jannuzzi (2016b) empregou-se o termo Auditoria Operacional para designar avaliações dessa natureza. Preferiu-se aqui precisar o conceito com o novo termo - Avaliações de Conformidade- sem ainda mitigar confusões com tipos de trabalho realizados pelos órgãos de controle público (TCU, 2010a; 2010b). Empregar um termo como Auditoria de Performance (PerformanceAudit) não pareceu apropriado para retratar a ênfase procedimental da avaliação nesse contexto.

${ }^{19}$ Como reza a máxima: No Brasil, basta apenas mais uma lei, com apenas um parágrafo: Artigo $1^{\circ} \mathrm{e}$ único: É obrigatório obedecer a toda e qualquer lei estabelecida. Parágrafo $1^{\circ} \mathrm{e}$ único: revogam-se todas as disposições em contrário".

${ }^{20}$ A interdição de obras de infraestrutura ou de compras públicas por tempos muito estendidos tem consequências sociais e econômicas que precisam ser apreciadas pela sociedade. O custo social do deficit de vagas em creches ou de outros equipamentos públicos precisa ser explicitado; assim como parte do Custo Brasil decorrente de interdições.

${ }^{21}$ Pelo impreciso rótulo de pós-positivistas está se incluindo um contingente bastante heterogêneo de pesquisadores que partilham da concepção da ciência como atividade socialmente produzida e ritos de validação construídos. Fosse esse texto uma discussão no âmbito dos Estudos Sociais da Ciência essa imprecisão não seria certamente aceitável.

22 Deslegitimam-se políticas e descartam-se programas por meio de evidências e estudos em que as escolhas metodológicas parecem pré-determinar os resultados, como parece ter sido os casos do Programa Nacional de Acesso ao Ensino Técnico e Emprego (Pronatec) e aos Programa Mais Educação (extensão de carga horária com atividades complementares diárias em escolas do Ensino Fundamental, com maior concentração de crianças de baixa renda e beneficiárias do Bolsa Família). Há mesmo situações em que se negam ou se desconsideram conjuntos de estudos realizados por diversas instituições e pesquisadores acerca de méritos de políticas baseado em supostos pouco transparentes, como a determinação de corte de 30\% da dotação orçamentária do Programa Bolsa Família em 2015, proposto pelo Relator do Orçamento, aparentemente como apoio do Ministério da Fazenda. 


\begin{abstract}
${ }^{23}$ Estratégias retóricas que, inclusive, são empregadas nesse texto como a preferência por citações literais em detrimento de paráfrases, para evidenciar a corroboração de diversos autores às discussões aqui apresentadas. O uso dos anglicismos Evidence-based, Rules-dictated e Equity-guide também poderia ser enquadrado nessa estratégia.

${ }^{24}$ Se é fato que as situações mais conhecidas de judicialização nas políticas públicas caracterizam-se pela consagração do direito individual em relação ao coletivo, há outras situações em que o interesse comum pode prevalecer sobre o individual, como no caso relatado por Sundfeld (2002). Nessa situação, a necessidade de promover ações domiciliares de combate à dengue, como pulverizações e coleta de pneus, vasos e outros depósitos que poderiam favorecer a multiplicação do mosquito transmissor, seria certamente entendida como meritória e válida sobre a decisão de morador que impedisse a ação, sob o argumento do princípio da inviolabilidade do domicílio particular. O interesse comum em garantir a salubridade ambiental seria um valor maior a garantir que o eventual e episódico transtorno ao morador. Frente a quadro de desmonte do conjunto de direitos sociais, trabalhistas e individuais por que passa o país, a judicialização de políticas públicas pode vir a ser um recurso de resistência republicana importante. Isso se as decisões judiciais contemplarem o interesse público de fato e não de categorias profissionais voltando ao contexto das Caixas de Seguridade dos anos 1920- e sobretudo se o Judiciário não mudar o entendimento acerca da constitucionalização dos direitos sociais.
\end{abstract}

\title{
Bibliografia
}

ARAÚJO, P.S. Feyerabend e o pluralismo. In; VIDEIRA, A.A.P. (org) Perspectivas contemporâneas em filosofia da ciência. Rio de Janeiro: Ed.Uerj, 2012, p.131-164.

BARBOSA, Fo.,F.H. et al. Pronatec Bolsa-Formação Uma Avaliação Inicial sobre Reinserção no Mercado de Trabalho Formal. Encontro Nacional da ANPEC, Florianópolis, 8 a 11 de dezembro, 2015.

CAMPELLO, T.; FALCÃO,T. e COSTA, P.V. O Brasil Sem Miséria. Brasília: MDS, 2014.

ECHEVERRÍA, J. Interdisciplinariedad y convergência tecnocientífica nano-bio-info-cogno. Sociologias, Porto Alegre, ano 11, v.22, p.22-53, jul/dez 2009.

FEYERABEND, P. Contra o Método. São Paulo: Ed.Unesp, 2011.

FOUREZ, G. A construção das Ciências. São Paulo: Ed. Unesp, 1995.

GERTLER, P. et al. Avaliação de impacto na prática. Washington, Banco Mundial, 2015.

HABERMAS, J. A lógica das Ciências Sociais. Petrópolis: Vozes, 2009.

HOWLETT, M.; RAMESH, M; PERL, A. Política pública, seus ciclos e subsistemas. Rio de Janeiro: Campus, 2013.

IEO. Evaluation of the contribution of UNDP Global and regional Human Development Reports to the public policy processes. New York: PNUD, 2016.

INEP. Indicador para mensurar a complexidade da gestão nas escolas a partir dos dados do Censo Escolar da Educação Básica. NOTA TÉCNICA Nº 040/2014. Brasília, 2014.

JANNUZZI, P.M. Indicadores para Avaliação Sistêmica de Programas Sociais: o caso Pronatec. Estudos em Avaliação Educacional, v. 27, n. 66, p. 624-661, set./dez. 2016 a.

JANNUZZI, P.M. Monitoramento e avaliação de programas sociais: uma introdução aos conceitos e técnicas. Campinas: Alínea, 2016b.

KERSTENETZKY, C.L. Políticas Sociais: focalização ou universalização? Revista de Economia Política, vol. 26, n 4 (104), pp. 564-574, outubro-dezembro/2006.

KUHN, T. A Estrutura da Revoluções Científicas. São Paulo: Perspectiva, 1992.

LA ROVERE, R. The consultative group on international agricultural research approach to impact evaluation on environment and natural resources management. In UITTO,J.I. (org) Evaluating environment in international development. New York: UNEP/Routledge, 2014, p.277-288. 
LATOUR, B. Ciência em ação: como seguir cientistas e engenheiros sociedade afora. São Paulo: Unesp, 2000.

MINAYIO,C. et al. Avaliação por triangulação de métodos: abordagem de programas sociais. Rio de Janeiro: Ed. Fiocruz, 2005.

MORAL-ARCE, I. Elección del método de evaluación cuantitativa de una política pública: buenas prácticas en América Latina y la Unión Europea. Madrid: EuroSocial, 2014. (Documentos de Trabajo, n. 6).

MORENO, L. et al. Los sistemas de bienestar europeos tras la crisis económica. Madrid : EuroSocial/ IILA , 2014.

POMBO, O. Práticas interdisciplinares. Sociologias, Porto Alegre, ano 8, v.15, p.208-249, jan/jul 2006.

PORTER,T. Thrust in numbers. New Jersey: PUF, 1996.

RAVAILLON, M. Should the randomists rule? Bekerley Eletronic Press, p.1-5, fev. 2009.

SACCO, F. O caráter social da ciência e os seus desafios na contemporaneidade. In: ROBERT,P. et al (orgs). Metodologia em Ciências Sociais Hoje. Jundiaí: Pacco Editorial, 2016, vol.1, p.117-136.

SAGI. SAGI: informação e conhecimento para as políticas de desenvolvimento social. 1ed. Brasilia, 2016.

SARMENTO, DANIEL. O neoconstitucionalismo no Brasil: riscos e possibilidades. In: FELLET, André Luiz Fernandes; PAULA, Daniel Giotti de; NOVELINO, Marcelo. As novas faces do ativismo judicial. Salvador: Jus Podivm, 2011, p. 73-113.

SUNDFELD, CARLOS ARI. Vigilância epidemiológica e direitos constitucionais. Revista de Direito Sanitário, v. 3, n.2, julho 2002, p. 90-106.

TCU. Padrões de auditoria de conformidade. Brasilia, 2010a.

TCU. Manual de Auditoria Operacional. Brasilia, 2010b.

UITTO, J. I. Evaluating environment in international development. In (org)

Evaluating environment in international development. New York: UNEP/Routledge, 2014, p.3-16.

VAITSMAN, J.; PAES-SOUSA, R. Avaliação de programas e transparência da gestão pública. ENAP. Reflexões para lbero-América: Avaliação de Programas Sociais. Brasilia, 2009, p.11-23.

VALLE, V.R.L. Judicialização das políticas no Brasil: até onde nos podem levar as asas de Ícaro. Themis, Coimbra, n.20-21, p.185-210, 2011.

WEISS, C. Evaluation research. New Jersey: Prentice Hall, 1998.

WEISS, C. Where Politics and Evaluation Research Meet. Evaluation Practice, 14 (1): 93-106, 1993.

WORTHERN, B.R. et al. Avaliação de programas: concepções e práticas. São Paulo: EdUsp/Ed. Gente, 2004

YANES, P. La experiencia de evaluación de programas sociales en la Ciudad de México. ENAP. Reflexões para Ibero-América: Avaliação de Programas Sociais. Brasilia, 2009, p.79-88.

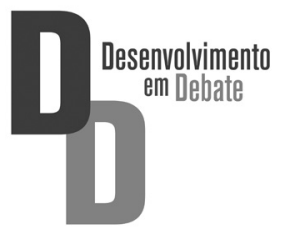

